\title{
Analysis of meniscal degeneration and meniscal gene expression
}

\author{
Yubo Sun ${ }^{1 *}$, David R Mauerhan ${ }^{1}$, Patrick R Honeycutt ${ }^{1}$, Jeffrey S Kneisl ${ }^{1}$, James H Norton ${ }^{2}$, Edward N Hanley Jr${ }^{1}$, \\ Helen E Gruber ${ }^{1}$
}

\begin{abstract}
Background: Menisci play a vital role in load transmission, shock absorption and joint stability. There is increasing evidence suggesting that OA menisci may not merely be bystanders in the disease process of OA. This study sought: 1) to determine the prevalence of meniscal degeneration in OA patients, and 2) to examine gene expression in OA meniscal cells compared to normal meniscal cells.
\end{abstract}

Methods: Studies were approved by our human subjects Institutional Review Board. Menisci and articular cartilage were collected during joint replacement surgery for OA patients and lower limb amputation surgery for osteosarcoma patients (normal control specimens), and graded. Meniscal cells were prepared from these meniscal tissues and expanded in monolayer culture. Differential gene expression in OA meniscal cells and normal meniscal cells was examined using Affymetrix microarray and real time RT-PCR.

Results: The grades of meniscal degeneration correlated with the grades of articular cartilage degeneration $(r=$ $0.672 ; \mathrm{P}<0.0001$ ). Many of the genes classified in the biological processes of immune response, inflammatory response, biomineral formation and cell proliferation, including major histocompatibility complex, class II, DP alpha 1 (HLA-DPA1), integrin, beta 2 (ITGB2), ectonucleotide pyrophosphatase/phosphodiesterase 1 (ENPP1), ankylosis, progressive homolog $(A N K H)$ and fibroblast growth factor 7 (FGF7), were expressed at significantly higher levels in OA meniscal cells compared to normal meniscal cells. Importantly, many of the genes that have been shown to be differentially expressed in other OA cell types/tissues, including ADAM metallopeptidase with thrombospondin type 1 motif 5 (ADAMTS5) and prostaglandin E synthase (PTGES), were found to be expressed at significantly higher levels in OA meniscal cells. This consistency suggests that many of the genes detected in our study are diseasespecific.

Conclusion: Our findings suggest that $O A$ is a whole joint disease. Meniscal cells may play an active role in the development of OA. Investigation of the gene expression profiles of OA meniscal cells may reveal new therapeutic targets for OA therapy and also may uncover novel disease markers for early diagnosis of OA.

\section{Background}

Osteoarthritis (OA) is a disease characterized by the breakdown of articular cartilage and the formation of osteophytes. However, it has been gradually realized that $\mathrm{OA}$ is not merely an articular cartilage disease, but a disease of the whole joint $[1,2]$. OA synovial membrane and subchondral bone have drawn considerably attention recently. Aberrant gene expression in OA synovium, OA fibroblast-like synoviocytes (FLS) and OA

\footnotetext{
* Correspondence: yubo.sun@carolinas.org
'Department of Orthopaedic Surgery, Carolinas Medical Center, PO Box

* Correspondence: yubo.sun@carolinas.org
1'Department of Orthopaedic Surgery, Carolinas Medical Center, PO Box 32861, Charlotte, NC 28232, USA
}

subchondral bone has been detected [3-6]. These findings suggest that $\mathrm{OA}$ synoviocytes and subchondral bone cells may be involved in the disease process of OA. Few studies have investigated the potential role of OA meniscal cells in the disease process of OA. The knee menisci are specialized tissues that play a vital role in load transmission, shock absorption and joint stability. Knee menisci may absorb most of the shock generated at the joint because their combined mass is greater than that of the articular cartilage. The current dogma is that menisci protect the articular cartilage, but play a minimal role in the disease process of OA unless they are injured. However, increasing evidence suggests that knee 
menisci may not be passive bystanders in the disease process of OA. It has been reported that meniscal degeneration is a feature of OA knee joints as revealed by magnetic resonance imaging $[7,8]$. There is a strong association between meniscal damage/degenerative tears and cartilage loss [9]. In addition, it has been found that meniscal degeneration contributes to joint space narrowing [10]. Taken together, these findings and observations suggest that pathological changes and extracellular matrix degeneration also occur in OA menisci. OA menisci, similar to OA synovial membrane and OA subchondral bone, may play an active role in the disease process of OA.

In the present study, we examined the prevalence of meniscal degeneration in OA patients who underwent joint replacement surgery, and analyzed the correlation between the degeneration of menisci and the degeneration of articular cartilage. We also examined differential gene expression between OA meniscal cells and normal meniscal cells to test the hypothesis that OA meniscal cells are different from normal meniscal cells and may display a disease-specific gene expression profile. The determination of the differential gene expression between $\mathrm{OA}$ and normal meniscal cells may not only provide experimental evident to support our hypothesis, but also may reveal new therapeutic targets for OA therapy and uncover novel disease markers for early diagnosis of OA.

\section{Methods}

\section{Menisci and articular cartilage specimens}

Menisci and articular cartilage specimens were collected from OA patients who underwent joint replacement surgery and from osteosarcoma patients who underwent lower limb amputation surgery with the approval of the authors' Institutional Review Board. The need for informed consent was waived since the menisci and articular cartilage were surgical waste of routine joint replacement surgery and lower limb amputation surgery, and there was no patient private information being collected. Specimens were transported to the laboratory from the operation room at our hospital in sterile tissue culture medium. The medial menisci and the medial articular cartilage of the tibia were graded (by DRM, PRH and YS) according to following scales. For the medial meniscus: $0=$ normal appearing surface; $1=$ minimal fibrillation and degeneration; $2=$ moderate fibrillation and degeneration; 3 = severe fibrillation and degeneration, no tears; $4=$ severe fibrillation and degeneration, multiple incomplete tears, or complete tears. For medial articular cartilage of the tibia: $0=$ normalappearing surface; 1 = minimal fibrillation and degeneration; 2 = erosion extending to middle layers; 3 = erosion extending into the deep layers; $4=$ erosion extending to the subchondral bone, and $5=$ the majority of articular cartilage completely absent.

\section{Preparation and culture of meniscal cells}

Dulbecco's modified eagle medium, fetal bovine serum, stock antibiotic and antimycotic mixture were products of Invitrogen (Carlsbad, CA). Meniscal cells were isolated from meniscal specimens as previously described [11]. Briefly, when meniscal specimens were arrived in sterile tissue culture medium, the central region of the medial meniscus was incised, and processed to remove fatty and synovial tissues. These meniscal specimens were then minced into small pieces $(3 \mathrm{~mm} \times 3 \mathrm{~mm})$, and cultured in $100 \mathrm{~mm}$ plates at $37^{\circ} \mathrm{C}$ in medium containing $0.5 \%$ antibiotic/antimycotic solution and $10 \%$ serum. Every three days, medium was changed. Meniscal cells proliferated, migrated out the tissues, attached to the plate and expanded. When meniscal cells reached $80 \%$ confluence, they were replated and expanded in monolayer culture. Passage two cells were used in all studies. Meniscal cells prepared from meniscal specimens derived from osteosarcoma patients were used as normal control meniscal cells.

\section{RNA extraction and microarrays}

OA meniscal cells and normal meniscal cells (passage 2) were plated in $100 \mathrm{~mm}$ plates at $75 \%$ confluence. On the second day, medium containing $1 \%$ serum was added and cells were cultured for twenty-four hours. Medium (1\% serum) was changed again and cells cultured for another twenty-four hours. Total RNA was extracted using Trizol reagent (Invitrogen, Carlsbad, $\mathrm{CA}$ ), and purified using Oligotex kit (Qiagen, Valencia, CA). Microarray analyses were performed using these RNA samples. For microarray analysis, double stranded DNA was synthesized from RNA samples using SuperScript double-stranded cDNA synthesis kit (Invitrogen, Carlsbad, CA). The DNA product was purified using GeneChip sample cleanup module (Affymetrix, Santa Clara, CA). cRNA was synthesized and biotin labeled using BioArray high yield RNA transcript labeling kit (Enzo Life Sciences, Farmingdale, NY). The product was purified using GeneChip sample cleanup module and subsequently chemically fragmented. The fragmented, biotinylated cRNA was hybridized to HG-U133_Plus_2 gene chip (Affymetrix, Santa Clara, CA) using Affymetrix Fluidics Station 400. The fluorescent signal was quantified during two scans by Agilent Gene Array Scanner G2500A (Agilent Technologies, Palo Alto, CA), and GeneChip operating Software (Affymetrix, Santa Clara, CA).

\section{Real-time RT-PCR}

cDNA was synthesized using TaqMan ${ }^{\circ}$ Reverse Transcription Reagents (Applied Biosystems, Inc., University Park, IL). Quantification of relative transcript levels for selected genes and the housekeeping gene 
glyceraldehyde 3-phosphate dehydrogenase (GAPDH) was performed using the ABI7000 Real Time PCR system (Applied Biosystems, Inc., University Park, IL). TaqMan $^{\circ}$ Gene Expression assays were used, which contains a FAM-MGB probe for fluorescent detection. cDNA samples were amplified with an initial Taq DNA polymerase activation step at $95^{\circ} \mathrm{C}$ for $10 \mathrm{~min}$ utes, followed by 40 cycles of denaturation at $95^{\circ} \mathrm{C}$ for 15 seconds and annealing at $60^{\circ} \mathrm{C}$ for one minute. For each gene, $\mathrm{Ct}$ values were obtained in triplicates. Fold change was calculated [12] and the expression level of the genes of interest was normalized to GAPDH. Each real time RT-PCR experiment was repeated twice in triplicate.

\section{Statistical Analysis}

The Spearman's correlations between the grades of meniscal degeneration and the grades of articular cartilage degeneration were calculated with $\mathrm{SAS}^{\circ}$ software (version 9.1). A two-tailed $p$-value of $<0.05$ was considered statistically significant. For microarray analysis, Genesifter software (VizX Labs, Seattle, WA) was used to determine fold changes in gene expression, and gene ontologies. Statistical significance was determined using the Student $\mathrm{t}$-test $(\mathrm{p}<0.05)$. A correction factor for false discovery rate was applied using the Benjamini and Hochberg method [13].

\section{Results}

\section{Degeneration of menisci in OA patients}

Demographic patient features and assigned grades are presented in Table 1. All menisci had signs of degeneration. More than $80 \%$ menisci showed signs of severe degeneration (grade 4 or grade 3). Representative images of grade $4 \mathrm{OA}$ menisci and grade 0 normal control menisci are shown in Figure 1. Grade 4 OA menisci displayed discolorations and an extremely rough surface. Severe degeneration and fissures/tears were apparent. In contrast, grade 0 control menisci displayed a smooth, white and glistening surface, with no any signs of degeneration.

The relationship between the grade of menisci and the grade of articular cartilage was examined. A correlation between the grade of menisci and the grade of articular cartilage was found. The Spearman's correlation coefficient $(\mathrm{r})$ was $0.672(\mathrm{p}<0.0001)$. Of the seventeen OA patients who had grade 5 (the highest grade of articular cartilage degeneration) articular cartilage, fourteen patients (82\%) had grade 4 medial meniscus (the highest grade of meniscal degeneration) and three patients had grade 3 medial meniscus. Of the nineteen OA patients who had grade 4 articular cartilages, ten patients had grade $4(58.82 \%)$ and seven had grade $3(41.17 \%)$ medial meniscus. Only two patients had grade $2(0.11 \%)$ medial meniscus.
Table 1 Demographic data and grades of articular cartilage and menisci*

\begin{tabular}{|c|c|c|c|}
\hline I & Cartilage Grade & \# Subjects & Mean Age \pm SD \\
\hline & 0 & $1 \mathrm{~F}$ & 39 \\
\hline & 0 & $1 \mathrm{~F}$ & 12 \\
\hline & 0 & $1 \mathrm{M}$ & 43 \\
\hline & 2 & $3 \mathrm{~F}, 1 \mathrm{M}$ & $62 \pm 13$ \\
\hline & 3 & $6 \mathrm{~F}, 5 \mathrm{M}$ & $64 \pm 9$ \\
\hline & 4 & $15 \mathrm{~F}, 4 \mathrm{M}$ & $62 \pm 11$ \\
\hline & 5 & $12 \mathrm{~F}, 5 \mathrm{M}$ & $67 \pm 9$ \\
\hline \multirow[t]{7}{*}{ II } & Meniscus Grade & \# Subjects & Mean Age \pm SD \\
\hline & 0 & $1 \mathrm{~F}$ & 39 \\
\hline & 0 & $1 \mathrm{~F}$ & 12 \\
\hline & 0 & $1 \mathrm{M}$ & 43 \\
\hline & 2 & $4 \mathrm{~F}, 3 \mathrm{M}$ & $57 \pm 12$ \\
\hline & 3 & $12 \mathrm{~F}, 6 \mathrm{M}$ & $64 \pm 9$ \\
\hline & 4 & $20 \mathrm{~F}, 6 \mathrm{M}$ & $66 \pm 9$ \\
\hline
\end{tabular}

*The first three patients are osteosarcoma patients. The rest fifty-one patients are OA patients. F, female; $M$, male

\section{Differential gene expression}

Microarray analyses of the differential gene expression between OA meniscal cells prepared from menisci (grade 4) derived from five OA patients and normal meniscal cells prepared from menisci (grade 0) derived from three osteosarcoma patients were carried out as described in Methods. The row microarray data can be found in Gene Expression Omnibus (GEO; http://www. ncbi.nlm.nih.gov/projects/geo/) with the accession

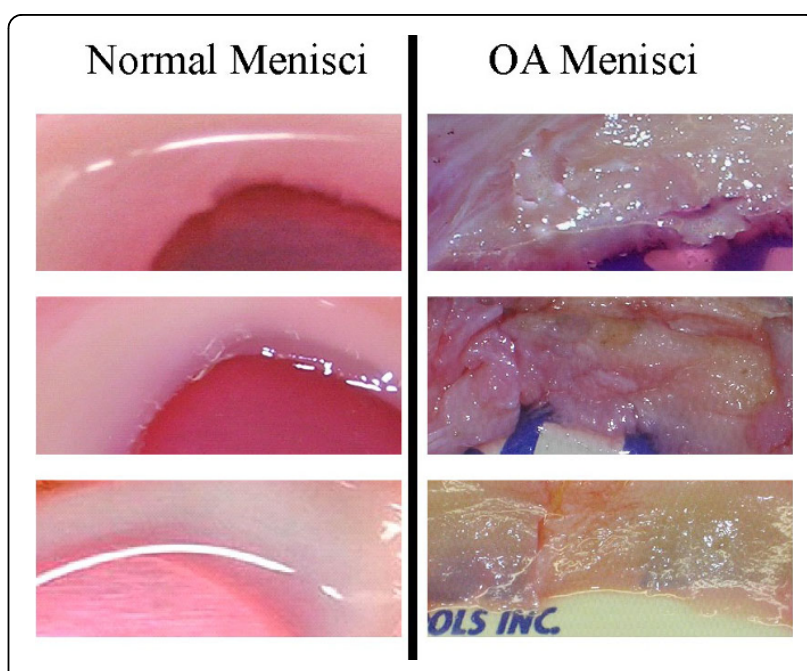

Figure 1 Representative photos of normal control menisci and OA menisci. Control menisci (left, top to bottom) were obtained from a 39 year old female osteosarcoma patient, a 43 year old male osteosarcoma patient and a 12 year old female osteosarcoma patient underwent lower limb amputation surgery. OA menisci (right, top to bottom) were obtained from a 65 year old female OA patient, a 67 year old female OA patient and a 50 year old female OA patient. 
number \#GSE19060. Table 2 presents the demographic data of the meniscal specimens which were the basis of this analysis. Of more than 50,000 transcripts examined, 505 transcripts that displayed differential gene expression (more than 1.2 fold) were identified; 149 transcripts were expressed at significantly higher levels and 356 transcripts at significantly lower levels in OA meniscal cells compared to normal meniscal cells. The differentially expressed genes were classified according to gene ontology category biological process using GeneSifter software (VizX Labs, Seattle, WA). Selected genes, which fell into specific biological processes previously implicated in OA or suspected to play a role in OA, or displayed a distinct expression pattern, are listed in Table 3.

We were particularly interested in identifying distinct differential gene expression patterns. As shown in Table 3 , distinct differential gene expression patterns were apparent. For example, of the seven differentiallyexpressed genes classified in the immune response biological process, five genes had elevated expressions but only two genes had decreased expression in OA meniscal cells compared to the control meniscal cells. Of the three differentially-expressed genes classified in the inflammation response biological process, cytokine production biological process, calcium ion transport biological process or the biomineral formation biological process, all these genes had elevated expression in OA meniscal cells compared to the control meniscal cells. Of the four differentially-expressed genes classified in the regulation of phosphate metabolic process, three genes had elevated expression but only one gene had decreased expression in OA meniscal cells compared to the control meniscal cells. Of the eighteen genes classified in the cell proliferation biological process, thirteen genes had elevated expression but only five genes had decreased expression in OA meniscal cells compared to the control meniscal cells. Similar distinct expression patterns were also found in other categories of biological processes, including integrin-mediated signaling pathway

Table 2 Demographic data and grades of menisci that were used to prepare meniscal cells*

\begin{tabular}{|c|c|c|}
\hline Patients & Age/Gender/Diagnosis & Grade Meniscus \\
\hline A & 39/F (osteosarcoma) & 0 \\
\hline B & 43/M (osteosarcoma) & 0 \\
\hline $\mathrm{C}$ & 12/F (osteosarcoma) & 0 \\
\hline 1 & 65/F (OA patient) & 4 \\
\hline 2 & 56/F (OA patient) & 4 \\
\hline 3 & 50/F (OA patient) & 4 \\
\hline 4 & 52/F (OA patient) & 4 \\
\hline 5 & 61/M (OA patient) & 4 \\
\hline
\end{tabular}

* $\mathrm{F}$, female; $\mathrm{M}$, male; $\mathrm{OA}$, osteoarthritis and skeletal system/tissue development biological processes (Table 3).

In contrast, most of the genes with decreased expressions in OA meniscal cells compared to the control meniscal cells fell into a different set of biological processes. For example, of the ten differentially-expressed genes classified in the DNA repair biological process, nine genes had decreased expression but only one gene had elevated expression in OA meniscal cells compare to the control meniscal cells. Of the ninety-one differentially expressed genes classified in the cellular biosynthetic process biological process, seventy-four genes had decreased expression in OA meniscal cells and only seventeen genes had elevated expression (Partial results are listed in Table 3). These distinct distributions of the differentially-expressed genes in different sets of biological processes suggest that OA meniscal cells are different from normal meniscal cells. We also analyzed the differential gene expression between individual OA meniscal cells (OA1, OA2, OA3, OA4, and OA5) and the normal control meniscal cells together as a control group. Selected results are listed in Table 4.

\section{Validation of differential expression of selected genes}

The genes selected for validation by quantitative realtime PCR included seven genes that displayed elevated expression in OA meniscal cells compared to normal meniscal cells (Table 5). They were major histocompatibility complex, class II, DP alpha (HLA-DPA1), integrin, beta 2 (ITGB2), ectonucleotide phosphodiesterase 1 (ENPP1), ADAM metallopeptidase with thrombospondin type 1 motif 5 (ADAMTS5), prostaglandin E synthase (PTGES), etc. Matrix metalloproteinase 10 (MMP10), which displayed decreased expression in OA meniscal cells compared to normal meniscal cells, was also selected for validation. RNA sample extracted from OA1 meniscal cells (Table 4) and RNA sample (mixture) extracted from the three normal control meniscal cells were used in the quantitative real time RT-PCR experiments. As shown in Table 5, the differential expressions of these genes were confirmed.

\section{Discussion}

In the present study, we found that more than eighty five percent $(85.7 \%)$ of the OA patients who underwent joint replacement surgery in our Medical Center had severe degenerative menisci (grades 4 or 3 ), indicating that meniscal degeneration is common in OA patients. We also found that meniscal degeneration correlated positively with articular cartilage degeneration in OA patients. The Spearman's correlation coefficient $(r)$ was 0.672 ( $\mathrm{p}<0.0001)$. Our finding is consistent with previous reports that meniscal degeneration/tears is a feature of OA knee joints [7], that meniscal degeneration contributes to joint space narrowing [10], that there is a 
Table 3 Genes differentially expressed in OA meniscal cells compared to normal meniscal cells.

\begin{tabular}{lllll}
\hline Biological process & $\begin{array}{l}\text { Gene } \\
\text { Name }\end{array}$ & Gene ID & $\begin{array}{l}\text { Differ } \\
\text { Exp } \\
\text { (fold)* }\end{array}$ \\
\hline Immune response & & & \\
\hline HLA-DPA1 & M27487 & 5.3 & Major histocompatibility complex, class II, DP alpha 1 \\
\hline IFl6 & NM_022873 & 2.0 & Interferon, alpha-inducible protein 6 \\
\hline CFH & X04697 & 1.7 & Complement factor H \\
\hline CTSS & NM_004079 & 1.6 & Cathepsin S \\
\hline FYN & S74774 & 1.5 & FYN oncogene related to SRC, FGR, YES \\
\hline ILF2 & NM_004515 & -1.3 & Interleukin enhancer binding factor 2, 45 kDa \\
\hline PSMB9 & Al375915 & -1.2 & Proteasome (prosome, macropain) subunit, beta type, 9
\end{tabular}

Inflammatory

Response

\begin{tabular}{|c|c|c|c|c|}
\hline & ITGB2 & NM_000211 & 6.6 & Integrin, beta 2 (complement component 3 receptor 3 and 4 subunit) \\
\hline & $\mathrm{CFH}$ & X04697 & 1.7 & Complement factor $\mathrm{H}$ \\
\hline & BDKRB2 & NM_000623 & 1.3 & Bradykinin receptor B2 \\
\hline \multicolumn{5}{|l|}{ Cytokine production } \\
\hline & SRGN & NM_002727 & 2.8 & Serglycin \\
\hline & ARNT & Al768497 & 2.3 & Aryl hydrocarbon receptor nuclear translocator \\
\hline & INHBA & M13436 & 1.9 & Inhibin, beta A \\
\hline \multicolumn{5}{|l|}{ Calcium ion transport } \\
\hline & CACNA1C & F11066 & 1.5 & Calcium channel, voltage-dependent, L type, alpha $1 C$ subunit \\
\hline & FYN & $\mathrm{S} 74774$ & 1.5 & FYN oncogene related to SRC, FGR, YES \\
\hline & CHRNB2 & NM_000748 & 1.4 & Cholinergic receptor, nicotinic, beta 2 (neuronal) \\
\hline \multicolumn{5}{|l|}{ Biomineral formation } \\
\hline & ENPP1 & BF057080 & 1.7 & Ectonucleotide pyrophosphatase/phosphodiesterase 1 \\
\hline & SRGN & NM_002727 & 2.8 & Serglycin \\
\hline & ACVR2A & Al149508 & 1.5 & Activin A receptor, type $\| \mathrm{A}$ \\
\hline \multicolumn{5}{|l|}{ Cell proliferation } \\
\hline & ITGB2 & NM_000211 & 6.6 & Integrin, beta 2 (complement component 3 receptor 3 and 4 subunit) \\
\hline & FGF7 & NM_002009 & 4.1 & Fibroblast growth factor 7 (keratinocyte growth factor) \\
\hline & ELN & AA479278 & 2.5 & Elastin (supravalvular aortic stenosis, Williams-Beuren syndrome) \\
\hline & IGFBP7 & NM_001553 & 2.4 & Insulin-like growth factor binding protein 7 \\
\hline & SKAP2 & AB014486 & 2.2 & Src kinase associated phosphoprotein 2 \\
\hline & ARNT & Al768497 & 2.3 & Aryl hydrocarbon receptor nuclear translocator \\
\hline & FOXO1 & NM_002015 & 1.5 & Forkhead box $\mathrm{O} 1$ \\
\hline & BCAT1 & AL390172 & 1.5 & Branched chain aminotransferase 1, cytosolic \\
\hline & ACVR2A & Al149508 & 1.5 & Activin A receptor, type $\| \mathrm{A}$ \\
\hline & TCF7L2 & AA664011 & 1.4 & Transcription factor 7-like 2 (T-cell specific, HMG-box) \\
\hline & CHRNB2 & NM_000748 & 1.4 & Cholinergic receptor, nicotinic, beta 2 (neuronal) \\
\hline & TCFL5 & NM_006602 & 1.2 & Transcription factor-like 5 (basic helix-loop-helix) \\
\hline & NRP1 & AA609131 & -1.3 & Neuropilin 1 \\
\hline & PHB & AL560017 & -1.3 & Prohibitin \\
\hline & TBX5 & NM_000192 & -1.3 & T-box 5 \\
\hline & NCK2 & BC000103 & -1.2 & NCK adaptor protein 2 \\
\hline & PRPF19 & NM_014502 & -1.2 & PRP19/PSO4 pre-mRNA processing factor 19 homolog (S. cerevisiae) \\
\hline \multicolumn{5}{|l|}{$\begin{array}{l}\text { Integrin-mediated signaling } \\
\text { pathway }\end{array}$} \\
\hline & ITGB2 & NM_000211 & 6.6 & Integrin, beta 2 \\
\hline & ITGB8 & BF513121 & 3.6 & Integrin, beta 8 \\
\hline & ITGA11 & AF109681 & 1.5 & integrin, alpha 11 \\
\hline
\end{tabular}


Table 3: Genes differentially expressed in OA meniscal cells compared to normal meniscal cells. (Continued)

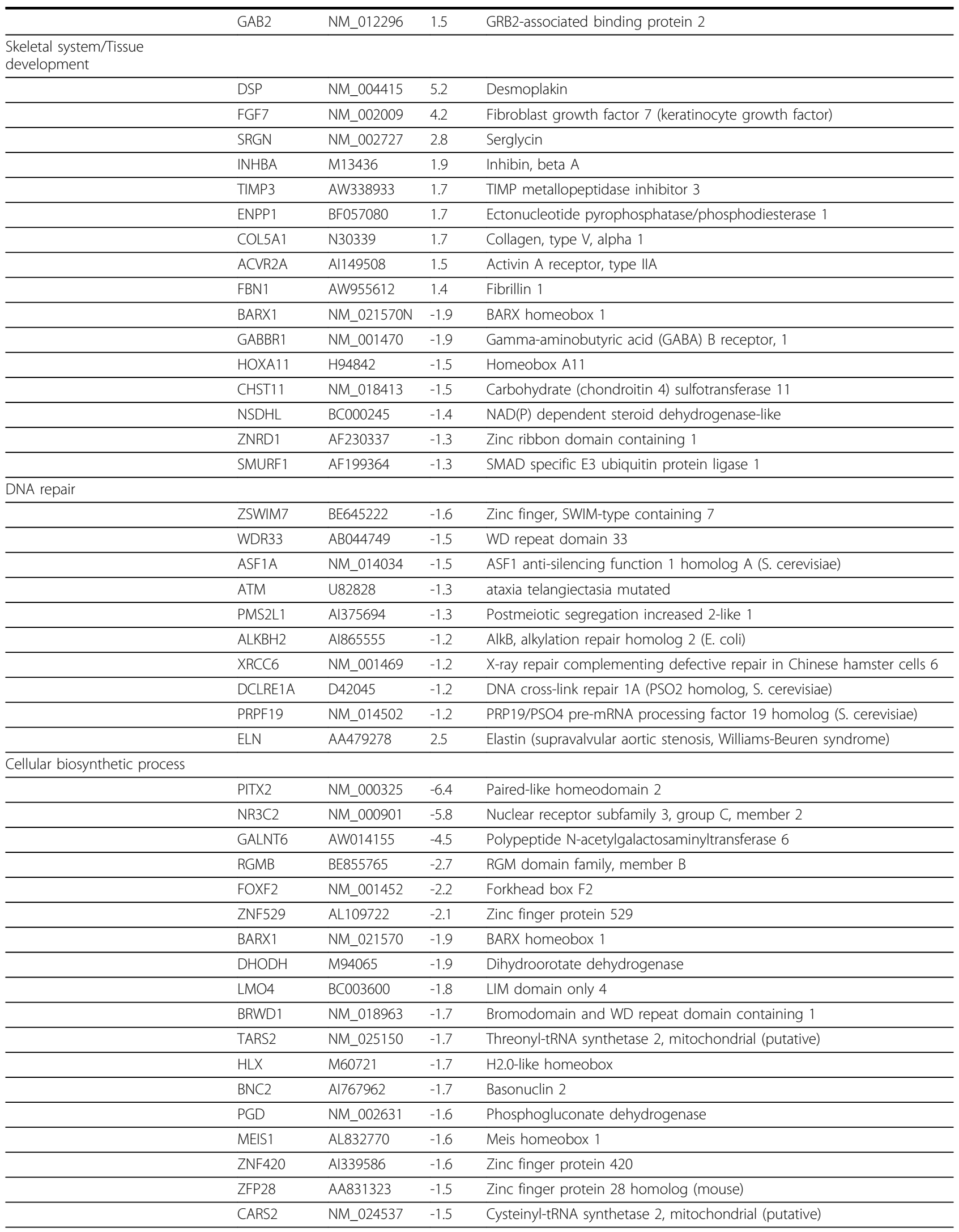


Table 3: Genes differentially expressed in OA meniscal cells compared to normal meniscal cells. (Continued)

\begin{tabular}{lllll}
\hline & HOXA11 & H94842 & -1.5 & Homeobox A11 \\
\hline PDLIM1 & BC000915 & 13.2 & PDZ and LIM domain 1 (elfin) \\
\hline ITGB2 & NM_000211 & 6.6 & Integrin, beta 2 (complement component 3 receptor 3 and 4 subunit) \\
\hline LMCD1 & NM_014583 & 3.5 & LIM and cysteine-rich domains 1 \\
\hline KRT7 & BC002700 & 3.1 & Keratin 7 \\
\hline ARNT & Al768497 & 2.3 & Aryl hydrocarbon receptor nuclear translocator \\
\hline ZNF415 & NM_018355 & 2.2 & Zinc finger protein 415 \\
\hline ZNF630 & AK000580 & 2.0 & Zinc finger protein 630 \\
\hline Miscellaneous & M13436 & 1.9 & Inhibin, beta A \\
\hline GALNT1 & U41514 & 1.7 & Polypeptide N-acetylgalactosaminyltransferase 1 \\
\hline ENPP1 & BF057080 & 1.7 & Ectonucleotide pyrophosphatase/phosphodiesterase 1 \\
\hline PTGES & AF010316 & 3.2 & Prostaglandin E synthase \\
\hline ADAMTS5 & NM_007038 & 1.7 & ADAM metallopeptidase with thrombospondin type 1 motif, 5 \\
\hline DSP & NM_004415 & 5.2 & Desmoplakin \\
\hline FMOD & NM_002023 & 2.7 & Fibromodulin \\
\hline SFRP4 & AW089415 & 3.4 & Secreted frizzled-related protein 4 \\
\hline MCAM & M28882 & 2.3 & Melanoma cell adhesion molecule \\
\hline TNXB & NM_004381 & -1.3 & Tenascin XB \\
\hline FUS & NM_004960 & -1.5 & Fusion (involved in t(12;16) in malignant liposarcoma) \\
\hline TBX5 & NM_000192 & -1.3 & T-box 5 \\
\hline
\end{tabular}

*Positive number indicates elevated expression (fold) in OA meniscal cells compared to normal meniscal cells. Negative number indicates decreased expression (fold) in OA meniscal cells compared to normal meniscal cells.

strong association between meniscal damage and cartilage loss [9], and that degenerative meniscal tears are positively associated with the severity of articular degeneration compared with other types of meniscal tears [14]. Taken together, our findings suggest that meniscal degeneration in $\mathrm{OA}$, similar to cartilage degeneration, is a major degenerative process regardless of whether it is primary or secondary. Further studies such as examination of the complete patient histories may provide information regarding the cause-result relationship between meniscal degeneration and cartilage degeneration.

If meniscal degeneration is a general feature of $\mathrm{OA}$, one would like to assess whether OA meniscal cells are different from normal meniscal cells and may play a role in the development of OA. To this end, we examined the differential gene expression between OA meniscal cells and normal control meniscal cells. We have recently reported that numerous genes that were classified in the biological process of immune response displayed elevated expression in OA FLS compared to rheumatoid arthritis (RA) FLS. HLA-DPA1 was expressed in OA FLS (hTERT-OA 13A FLS) 16 fold higher than that in RA FLS (hTERT-RA 516 FLS) [4]. Consistently, many genes that were classified in the biological process of immune response including $H L A$ $D P A 1$ also displayed elevated expression in OA meniscal cells (Table 3). The findings indicate that OA meniscal cells, similar to OA FLS, may be involved in the inflammatory process observed in OA.

Calcium-containing crystals are found in the joint fluid of up to $65 \%$ of OA patients, and the presence of these crystals correlates with the radiographic evidence of cartilaginous degeneration [15-18]. There is evidence indicating that crystals may promote joint degeneration [19-21]. Most recently, it was demonstrated that the inhibition of meniscal calcification by calcium phosphocitrate, a potent anti-calcification agent, was accompanied by a significant reduction in the degeneration of articular cartilage in Hartley guinea pigs [22]. These data suggest that excessive meniscal calcification may play a role in OA. However, there have been no studies to investigate the alterations in OA meniscal cells or to identify the candidate disease genes that are potentially responsible for the excessive meniscal calcification in OA. In the present study, we found that many genes which are involved in biomineral formation such as ENPP1 [23], in phosphate metabolic process such as ITGB2 and in calcium ion transport such as calcium channel, voltage-dependent, L type, alpha $1 \mathrm{C}$ subunit $(C A C N A 1 C)$ are expressed at an elevated levels in OA meniscal cells compared to normal meniscal cells. These findings are consistent 
Table 4 Genes differentially expressed in individual OA meniscal cells compared to normal meniscal cells.

\begin{tabular}{|c|c|c|c|c|c|c|c|}
\hline $\begin{array}{l}\text { Gene } \\
\text { Name } \\
\end{array}$ & Gene ID & OA1 & OA1 & OA3 & OA4 & OA5 & Description \\
\hline BST1 & NM_004334 & 3.9 & 3.4 & 3.3 & 1.6 & 2.2 & bone marrow stromal cell antigen 1 \\
\hline FGF9 & NM_002010 & 3.7 & 2.4 & 3.7 & 2.5 & 2.9 & Fibroblast growth factor 9 \\
\hline ACAN & NM_013227 & 2.4 & 1.6 & 1.6 & 0.0 & 1.6 & Aggrecan \\
\hline COL11A1 & $\mathrm{J} 04177$ & 0.0 & 11.5 & 5.8 & 2.2 & 3.6 & Collagen, type XI, alpha 1 \\
\hline ANKH & AL833238 & 0.0 & 1.8 & 1.7 & 1.5 & 1.8 & Ankylosis, progressive homolog (mouse) \\
\hline MGP & NM_000900 & 11.8 & 4.7 & 21.6 & 0.0 & 17.6 & Matrix Gla protein \\
\hline TUFT1 & NM_020127 & 2.8 & 2.7 & 1.9 & 0.0 & 0.0 & Tuftelin 1 \\
\hline TFIP11 & NM_012143 & 2.2 & 1.6 & 0.0 & 0.0 & 0.0 & Tuftelin interacting protein 11 \\
\hline IL20RB & AL578102 & 2.3 & 2.7 & 0.0 & 2.6 & 7.8 & Interleukin 20 receptor beta \\
\hline IL26 & NM_018402 & 1.7 & 1.6 & 1.6 & 0.0 & 3.0 & Interleukin 26 \\
\hline COL4A5 & AW052179 & -3.1 & -3.0 & -3.1 & -3.0 & -3.1 & Collagen, type IV, alpha 5 (Alport syndrome) \\
\hline MMP9 & NM_004994 & -2.2 & -2.1 & -2.1 & 0.0 & -2.2 & Matrix metallopeptidase 9 \\
\hline MMP10 & NM_002425 & -2.7 & -2.6 & -2.7 & -1.5 & -2.6 & Matrix metallopeptidase 10 \\
\hline MMP12 & NM_002426 & -2.1 & -2.0 & -2.1 & 0.0 & -2.1 & Matrix metallopeptidase 12 \\
\hline FZD10 & NM_007197 & -1.6 & -1.5 & -1.6 & -1.5 & -1.5 & Frizzled homolog 10 (Drosophila) \\
\hline CYTL1 & NM_018659 & -2.6 & -2.6 & -2.6 & -2.6 & -2.5 & Cytokine-like 1 \\
\hline $\mathrm{CHODL}$ & NM_024944 & -2.6 & -2.6 & -2.6 & & -2.6 & Chondrolectin \\
\hline
\end{tabular}

*Positive number indicates elevated expression (fold) in OA meniscal cells compared to normal meniscal cells. Negative number indicates decreased expression (fold) in OA meniscal cells compared to normal meniscal cells. 0.0 indicates there was no differential gene expression being detected.

with clinical observations that meniscal calcification is more severe in OA menisci $[24,25]$ and that calcium content in OA menisci is positively correlated with the stage of meniscal degeneration [26]. In addition to the genes listed in Table 3, several other genes that have been previously implicated in pathological calcification were also detected (Table 4). They were ankylosis progressive homolog $(A N K H)[27,28]$, matrix Gla protein $(M G P)[29,30]$ and tuftelin (TUFT1) [31-33]. Taken together, our findings suggest that OA meniscal cells may be actively involved in the meniscal calcification process in OA.

Many genes that have been previously found to be expressed at elevated levels in other types of OA cells or tissues such as in OA articular cartilage and OA bone were also detected in this study. They were integrin, beta 8 (ITGB8) [34], insulin-like growth factor binding protein 7 (IGFBP7) [34], fibromodul (FMOD) [28], cathepsin S (CTSS) [35], secreted frizzled-related protein 4 (SFRP4) [34], bone marrow stromal cell antigen 1 (BST1) [35], collagen, type XI, alpha 1 (COL11A1) [34], collagen, type $\mathrm{V}$, alpha 1 (COL5A1) [34], PTGES [36] and ADAMTS5 [37]. These genes were expressed at significantly elevated levels in OA meniscal cells compared to normal meniscal cells (Tables 3 and 4). ADAMTS5 is a major cartilage matrix degrading enzyme and has been implicated in articular cartilage degeneration previously $[38,39]$. The elevated expression of ADAMTS5 in OA meniscal cells suggests that ADAMTS5 may play a role in meniscal degeneration.

Table 5 Differential gene expression confirmed by real time RT-PCR*

\begin{tabular}{llccl}
\hline $\begin{array}{l}\text { Gene } \\
\text { name }\end{array}$ & Gene ID & $\begin{array}{c}\text { Differential Expression* } \\
\text { Microarray }\end{array}$ & $\begin{array}{c}\text { Differential Expression* RT- } \\
\text { PCR }\end{array}$ & Description \\
\hline HLA-DPA1 & M27487 & 5.3 & 10.5 & Major histocompatibility complex, class II, DP alpha \\
\hline ITGB2 & NM_000211 & 6.6 & 5.2 & Integrin, beta 2 \\
\hline PTGES & AF010316 & 3.2 & 3.4 & Prostaglandin E synthase \\
\hline ENPP1 & BF057080 & 1.7 & 2.1 & Ectonucleotide pyrophosphatase/phosphodiesterase 1 \\
\hline ADAMTS5 & BI254089 & 1.7 & 1.9 & ADAM metallopeptidase with thrombospondin type 1 \\
\hline IL26 & NM_018402 & 1.7 & 4.3 & motif, 5 \\
\hline TUFT1 & NM_020127 & 2.8 & 3.9 & Matrix metalloproteinase 1 \\
\hline MMP10 & NM_002425 & -2.7 & -3.1 & Matrix metalloproteinase 10 \\
\hline
\end{tabular}

*Differential Expression - the numbers are the ratio of the relative expression level of a specific gene in OA1 meniscal cells to the relative expression level of the specific gene in the control meniscal cells (mixture of RNA prepared from the three normal control meniscal cells). 
Furthermore, many genes that have been previously found to be expressed at decreased levels in other types of OA cells or tissues were also detected in this study. They are MMP10 [34], MMP12 [40], tenascin XB (TNXB) [34], fusion (FUS) [28], melanoma cell adhesion molecule (MCAM) [35], and T-box 5 (TBX5) [5]. These genes were expressed at decreased levels in OA meniscal cells compared to normal meniscal cells (Tables 3 and 4). The consistency between our findings and the previous findings provides strong support for our hypothesis that OA meniscal cells are different from normal meniscal cells and may play an active role in the development of OA.

Our study has some limitations which should be considered. The control meniscal cells we used were derived from the menisci of osteosarcoma patients and were not optimal normal control meniscal cells. To minimize this limitation, we only collected overtly normal-appearing meniscal and cartilage specimens (grade 0) from osteosarcoma patients whose tumors were located far away from the knee joints. In addition, we analyzed the differential gene expression using meniscal cells rather than using meniscal tissue specimens directly to eliminate the effect of different drugs that might be taken by OA and osteosarcoma patients at the time of surgery.

Most meniscal cells synthesize type I collagen as their major collagen product. The meniscal cells in the inner, central nonvascularized region of meniscus synthesize type II collagen. It is an open question at this time as to whether a single cell type exists in the meniscus that displays a fibroblast-like phenotype or a chondrocytelike phenotype depending on its environment, or whether two or more distinct cell types exist. Therefore, it is not absolutely certain at this time whether the differences in the gene expressions detected in this study reflect the overall differences between OA meniscal cells and the control meniscal cells or only reflect the differences between a subpopulation of OA meniscal cells and a subpopulation of the control meniscal cells. Another limitation is that the age of osteosarcoma patients was younger than the age of OA patients. Therefore, certain genes we detected may be age-related rather disease-specific. It is difficult to obtain agematched control meniscal specimens because osteosarcoma occurs often in younger patients while OA occurs mostly in older patients. We will continue this line of study when more age matched normal control meniscal specimens become available in the future. In spite of these limitations, the consistency between our findings and the previous findings that many of the genes we detected are also abnormally expressed in other OA cell types/tissues $[4,5,23,28,34-36,40]$ suggests that many of the differential gene expressions detected in this study are disease-specific.

\section{Conclusions}

Our findings suggest that $\mathrm{OA}$ is not merely a cartilage disease, but also a disease of the menisci. OA meniscal cells may play an active role in the disease process of OA. Investigation of the gene expression profile of OA meniscal cells compared to normal meniscal cells may reveal new therapeutic targets for OA therapy and uncover novel disease markers for early diagnosis of OA.

\section{Abbreviations}

OA: osteoarthritis; FLS: fibroblast-like synoviocytes; MMP: matrix metalloproteinase; ITGB: integrin: beta; ADAMTS5: metallopeptidase with thrombospondin type 1 motif 5; ANKH: ankylosis: progressive homolog; BST1: bone marrow stromal cell antigen 1; CACNA1C: calcium channel: voltage-dependent: $L$ type: alpha $1 \mathrm{C}$ subunit; COL5A1: collagen, type $\mathrm{V}$, alpha 1; COL11A1: collagen, type XI, alpha 1; CTSS: cathepsin S; ENPP1: ectonucleotide pyrophosphatase/phosphodiesterase 1; FGF7: fibroblast growth factor 7; FMOD: fibromodul; FUS: fusion; GAPDH: glyceraldehyde-3phosphate dehydrogenase; HLA-DPA1: major histocompatibility complex, class II, DP alpha 1; IGFBP7: insulin-like growth factor binding protein 7; MCAM: melanoma cell adhesion molecule; MGP: matrix Gla protein; PTGES: prostaglandin E synthase; SFRP4: secreted frizzled-related protein 4; TUFT1: tuftelin; TBX5: T-box 5; TNXB: tenascin XB.

\section{Acknowledgements}

This study is supported in part by Charlotte-Mecklenburg Education and Research Foundation Grant (to YS) and Mecklenburg County Medical Society Smith Arthritis Fund Grant (to YS). This study was performed at Carolinas Medical Center, Charlotte, NC.

\section{Author details}

'Department of Orthopaedic Surgery, Carolinas Medical Center, PO Box 32861, Charlotte, NC 28232, USA. ${ }^{2}$ Department of Biostatistics, Carolinas Medical Center, PO Box 32861, Charlotte, NC 28232, USA.

\section{Authors' contributions}

YS, HEG and ENH conceived the study and participated in design and coordination. YS wrote the manuscript. DRM and JSK provided surgical tissues and participated in the discussion of experimental results. HJN assisted with statistical analysis. PRH, DRM and YS graded menisci and articular cartilage. PRH prepared cell culture and extracted RNA. HEG assisted with manuscript preparation. All authors read and approved the final manuscript.

\section{Competing interests}

The authors declare that they have no competing interests.

Received: 26 August 2009

Accepted: 28 January 2010 Published: 28 January 2010

\section{References}

1. Goldring MB, Goldring SR: Osteoarthritis. J Cell Physiol 2007, 213:626-634.

2. Samuels J, Krasnokutsky S, Abramson SB: Osteoarthritis: a tale of three tissues. Bull NYU Hosp Jt Dis 2008, 66:244-250.

3. H Kato, Matsumine A, Wakabayashi T, Hasegawa M, Sudo A, Shintani K, Fukuda A, Kato K, Ide N, Orita S, Hasegawa T, Matsumura C, Furukawa M, Tasaki T, Sonoda H, Uchida A: Large-scale gene expression profiles, differentially represented in osteoarthritic synovium of the knee joint using CDNA microarray technology. Biomarkers 2007, 12:384-402.

4. Sun Y, Mauerhan DR, Firestein GS, Loeffler BJ, Hanley EN, Gruber HE: Telomerase transduced osteoarthritis fibroblast-like synoviocytes display a distinct gene expression profile. J Rheumatol 2009, 36:141-155.

5. Galligan CL, Baig E, Bykerk V, Keystone EC, Fish EN: Distinctive gene expression signatures in rheumatoid arthritis synovial tissue fibroblast cells: correlates with disease activity. Genes Immun 2007, 8:480-491.

6. Hopwood B, Tsykin A, Findlay DM, Fazzalari NL: Microarray gene expression profiling of osteoarthritic bone suggests altered bone 
remodelling, WNT and transforming growth factor-beta/bone morphogenic protein signalling. Arthritis Res Ther 2007, 9:R100.

7. Chan WP, Lang P, Stevens MP, Sack K, Majumdar S, Stoller DW, Basch C, Genant HK: Osteoarthritis of the knee: comparison of radiography, CT, and MR imaging to assess extent and severity. AJR Am J Roentgenol 1991, 157:799-806.

8. Bennett $L D$, Buckland-Wright JC: Meniscal and articular cartilage changes in knee osteoarthritis: a cross-sectional double-contrast macroradiographic study. Rheumatology 2002, 41:917-923.

9. Hunter DJ, Zhang YQ, Niu JB, Tu X, Amin S, Clancy M, Guermazi A, Grigorian M, Gale D, Felson DT: The association of meniscal pathologic changes with cartilage loss in symptomatic knee osteoarthritis. Arthritis \& Rheumatism 2006, 54:795-801.

10. Hunter DJ, Zhang YQ, Tu X, Lavalley M, Niu JB, Amin S, Guermazi A, Genant H, Gale D, Felson DT: Change in joint space width: hyaline articular cartilage loss or alteration in meniscus?. Arthritis Rheum 2006, 54:2488-2495.

11. Gruber HE, Mauerhan D, Chow Y, Ingram JA, Norton HJ, Hanley EN Jr, Sun Y: Three-dimensional culture of human meniscal cells: extracellular matrix and proteoglycan production. BMC Biotechnol 2008, 8:54.

12. Pfaffl $M$, Meyer $H H$, Sauerwein $H$ : Quantification of insulin-like growth factor-1 (IGF-1) mRNA: development and validation of an internally standardised competitive reverse transcription-polymerase chain reaction. Exp Clin Endocrinol Diabetes 1998, 106:506-513.

13. Reiner A, Yekutieli D, Benjamini Y: Identifying differentially expressed genes using false discovery rate controlling procedures. Bioinformatics 2003, 19:368-375.

14. Christoforakis J, Pradhan R, Sanchez-Ballester J, Hunt N, Strachan RK: Is there an association between articular cartilage changes and degenerative meniscus tears?. Arthroscopy 2005, 21:1366-1369.

15. Carroll GJ, Stuart RA, Armstrong JA, Breidahl PD, Laing BA: Hydroxyapatite crystals are a frequent finding in osteoarthritic synovial fluid, but are not related to increased concentrations of keratan sulfate or interleukin 1 beta. The Journal of Rheumatology 1991, 18:861-866.

16. Derfus BA, Kurian JB, Butler JJ, Daft LJ, Carrera GF, Ryan LM, Rosenthal AK: The high prevalence of pathologic calcium crystals in pre-operative knees. J Rheumatol 2002, 29:570-574.

17. Felson DT, Anderson JJ, Naimark A, Kannel W, Meenan RF: The prevalence of chondrocalcinosis in the elderly and its association with knee osteoarthritis: the Framingham Study. The Journal of Rheumatology 1989, 16:1241-1245.

18. Nalbant S, Martinez JA, Kitumnuaypong T, Clayburne G, Sieck M, Schumacher HR Jr: Synovial fluid features and their relations to osteoarthritis severity: new findings from sequential studies. Osteoarthritis and Cartilage 2003, 11:50-54.

19. Cheung HS, Mitchell PG, Pledger WJ: Induction of expression of c-fos and c-myc protooncogenes by basic calcium phosphate crystal: effect of beta-interferon. Cancer Res 1989, 49:134-138.

20. McCarthy GM, Cheung HS, Abel SM, Ryan LM: Basic calcium phosphate crystal-induced collagenase production: role of intracellular crystal dissolution. Osteoarthritis Cartilage 1998, 6:205-213.

21. Sun $Y$, Zeng XR, Wenger $L$, Cheung HS: Basic calcium phosphate crystals stimulate the endocytotic activity of cells-inhibition by anti-calcification agents. Biochem Biophys Res Commun 2003, 312:1053-1059.

22. Cheung HS, Sallis JD, Demadis KD, Wierzbicki A: Phosphocitrate blocks calcification-induced articular joint degeneration in a guinea pig model. Arthritis Rheum 2006, 54:2452-2461.

23. Zhang Y, Brown MA, Peach C, Russell G, Wordsworth BP: Investigation of the role of ENPP1 and TNAP genes in chondrocalcinosis. Rheumatology (Oxford) 2007, 46:586-589.

24. Canhao H, Fonseca JE, Leandro MJ, Romeu JC, Pimentao JB, Costa JT, Queiroz MV: Cross-sectional study of 50 patients with calcium pyrophosphate dihydrate crystal arthropathy. Clin Rheumatol 2001, 20:119-122.

25. Brandes A, Muller KM: [Calcinosis of the meniscus. Morphologic and roentgenographic findings for zonal classification]. Pathologe 1995, 16:269-277.

26. Habata T, Ohgushi H, Takakura Y, Tohno Y, Moriwake Y, Minami T, Fujisawa Y: Relationship between meniscal degeneration and element contents. Biological Trace Element Research 2001, 79:247-256.
27. Williams CJ, Zhang Y, Timms A, Bonavita G, Caeiro F, Broxholme J, Cuthbertson J, Jones Y, Marchegiani R, Reginato A, Russell RG, Wordsworth BP, Carr AJ, Brown MA: Autosomal dominant familial calcium pyrophosphate dihydrate deposition disease is caused by mutation in the transmembrane protein ANKH. Am J Hum Genet 2002, 71:985-991.

28. Aigner T, Zien A, Gehrsitz A, Gebhard PM, McKenna L: Anabolic and catabolic gene expression pattern analysis in normal versus osteoarthritic cartilage using complementary DNA-array technology. Arthritis Rheum 2001, 44:2777-2789.

29. Yagami K, Suh JY, Enomoto-Iwamoto M, Koyama E, Abrams WR, Shapiro IM, Pacifici M, Iwamoto M: Matrix GLA protein is a developmental regulator of chondrocyte mineralization and, when constitutively expressed, blocks endochondral and intramembranous ossification in the limb. The Journal of Cell Biology 1999, 147:1097-1108.

30. Taylor BC, Schreiner PJ, Doherty TM, Fornage M, Carr JJ, Sidney S: Matrix Gla protein and osteopontin genetic associations with coronary artery calcification and bone density: the CARDIA study. Hum Genet 2005, 116:525-528.

31. Paine CT, Paine ML, Luo W, Okamoto CT, Lyngstadaas SP, Snead ML: A tuftelin-interacting protein (TIP39) localizes to the apical secretory pole of mouse ameloblasts. J Biol Chem 2000, 275:22284-22292.

32. Cerny R: [Mineralized dental enamel matrix proteins]. Bratis/ Lek Listy 2000, 101:288-293.

33. Deutsch D, Leiser Y, Shay B, Fermon E, Taylor A, Rosenfeld E, Dafni L, Charuvi K, Cohen Y, Haze A, Fuks A, Mao Z: The human tuftelin gene and the expression of tuftelin in mineralizing and nonmineralizing tissues. Connect Tissue Res 2002, 43:425-434.

34. Ijiri K, Zerbini LF, Peng H, Otu HH, Tsuchimochi K, Otero M, Dragomir C, Walsh N, Bierbaum BE, Mattingly D, van FG, Komiya S, Aigner T, Libermann TA, Goldring MB: Differential expression of GADD45beta in normal and osteoarthritic cartilage: potential role in homeostasis of articular chondrocytes. Arthritis Rheum 2008, 58:2075-2087.

35. Appleton CT, Pitelka V, Henry J, Beier F: Global analyses of gene expression in early experimental osteoarthritis. Arthritis Rheum 2007, 56:1854-1868.

36. Sato T, Konomi K, Yamasaki S, Aratani S, Tsuchimochi K, Yokouchi M, Masuko-Hongo K, Yagishita N, Nakamura H, Komiya S, Beppu M, Aoki H, Nishioka K, Nakajima T: Comparative analysis of gene expression profiles in intact and damaged regions of human osteoarthritic cartilage. Arthritis Rheum 2006, 54:808-817.

37. Plaas A, Osborn B, Yoshihara Y, Bai Y, Bloom T, Nelson F, Mikecz K, Sandy JD: Aggrecanolysis in human osteoarthritis: confocal localization and biochemical characterization of ADAMTS5-hyaluronan complexes in articular cartilages. Osteoarthritis Cartilage 2007, 15:719-734

38. Majumdar MK, Askew R, Schelling S, Stedman N, Blanchet T, Hopkins B, Morris EA, Glasson SS: Double-knockout of ADAMTS-4 and ADAMTS-5 in mice results in physiologically normal animals and prevents the progression of osteoarthritis. Arthritis Rheum 2007, 56:3670-3674.

39. Chia SL, Sawaji Y, Burleigh A, McLean C, Inglis J, Saklatvala J, Vincent T: Fibroblast growth factor 2 is an intrinsic chondroprotective agent that suppresses ADAMTS- 5 and delays cartilage degradation in murine osteoarthritis. Arthritis Rheum 2009, 60:2019-2027.

40. Davidson RK, Waters JG, Kevorkian L, Darrah C, Cooper A, Donell ST, Clark IM: Expression profiling of metalloproteinases and their inhibitors in synovium and cartilage. Arthritis Res Ther 2006, 8:R124.

\section{Pre-publication history}

The pre-publication history for this paper can be accessed here:http://www. biomedcentral.com/1471-2474/11/19/prepub

\section{doi:10.1186/1471-2474-11-19}

Cite this article as: Sun et al:: Analysis of meniscal degeneration and meniscal gene expression. BMC Musculoskeletal Disorders 2010 11:19. 